\title{
A!
}

This is an electronic reprint of the original article.

This reprint may differ from the original in pagination and typographic detail.

Kortela, Jukka; Jämsä-Jounela, Sirkka-Liisa

\section{Fuel moisture soft-sensor and its validation for the industrial BioPower 5 CHP plant}

Published in:

Applied Energy

DOI:

10.1016/j.apenergy.2012.12.049

Published: 01/01/2013

Document Version

Peer reviewed version

Please cite the original version:

Kortela, J., \& Jämsä-Jounela, S-L. (2013). Fuel moisture soft-sensor and its validation for the industrial

BioPower 5 CHP plant. Applied Energy, 105(105), 66-74. https://doi.org/10.1016/j.apenergy.2012.12.049

This material is protected by copyright and other intellectual property rights, and duplication or sale of all or part of any of the repository collections is not permitted, except that material may be duplicated by you for your research use or educational purposes in electronic or print form. You must obtain permission for any other use. Electronic or print copies may not be offered, whether for sale or otherwise to anyone who is not an authorised user. 


\title{
Fuel moisture soft-sensor and its validation for the industrial BioPower 5 CHP plant
}

\author{
Jukka Kortela, Sirkka-Liisa Jämsä-Jounela \\ Aalto University, School of Chemical Technology, P.O. Box 16100, FI-00076 Aalto, Finland
}

\begin{abstract}
This paper presents a soft-sensor for on-line monitoring of fuel moisture in a furnace. The method utilizes combustion power estimation and a dynamic model of the secondary superheater. In addition, the time delays in detecting changes in moisture content of the fuel are small enough for the method to be used for controlling air and fuel feed and preventing steam and pressure oscillations. To verify the fuel moisture soft-sensor, experiments were performed at a BioPower 5 CHP plant, which utilizes BioGrate combustion technology for very wet biomass fuels with a moisture content as high as $65 \%$. Finally, the results are analyzed and discussed. (C) 2013 Elsevier Ltd.
\end{abstract}

Keywords

Biomass, Combustion, Control, Fuel moisture, Industrial application

\section{Introduction}

The use of biomass fuel for heat and power production is growing due to increasing demands to replace fossil energy with renewable energy. Biomass fuel is usually a blend of different batches, for example, spruce bark and dry woodchips, and with a moisture content between $30 \%$ and $55 \%$ [1]. The varying moisture content of the fuel results in uncertainty about its energy content and complicates operation of combustors. It was found that exergy destruction is most extensive in the furnace [2,3]. The typical procedure to determine a fuel's moisture content in small or medium-scale grate furnaces is to analyze manually collected samples of each fuel batch delivered to the plant. This method, however, is not accurate enough to predict the moisture content of the fuel mix that later actually enters the furnace. A change in moisture content of the fuel has to be detected within seconds so that the control system is able to make correct adjustments to the combustion air supply and the fuel feed system. There is, thus, a strong need to supply control systems or operators with information about moisture content for necessary adjustments of the combustors [4].

On-line measurements of fuel moisture content can be carried out as direct measurements or using indirect methods. Direct measurements include the use of dual-energy X-ray absorptiometry (DXA), near infrared spectroscopy (NIR), radio frequency (RF), microwave, and nuclear magnetic resonance (NMR) [5]. Nordell and Vikterlöf [6] performed a series of experiments to verify if dual energy X-rays can be utilized as a technique to measure the moisture content of biofuels. They used standard medical X-ray equipment in the tests, which were carried out on ten different kinds of wood fuels, and grouped the results into three main groups depending on the fuel type, i.e. wood-based, peat-based, willow and mixtures of these. A standard error of performance (SEP) of $2 \%$ was achieved for each individual fuel type. However, when the results were combined, correction coefficients were needed to take into account the different amounts of carbon content of the different fuels. So more research in this area is needed that takes into account varying fuel compositions.

Several studies have been made using NIR on different types of peat and wood. Ayalew and Ward [7] tested NIR on three peat types (low-, medium-, and high-density peats) whose moisture content ranged from ca. 
$33 \%$ to $63 \%$. Based on the computed standard error of estimate, the $95 \%$ confidence limits of the moisture meter were $2.75,1.75$, and 3.2, respectively, for low-, medium-, and high-density peats. However, when all the peat types were grouped together, the $95 \%$ confidence limit increased to the higher error value of 5.3. It is therefore necessary to be able to distinguish between peat types. In another study, Axrup et al. [8] evaluated NIR measurements with a silicone array spectrometer in an on-line analysis of wood chips and bark. They reported promising results with a root mean square error of prediction (RMSEP) of $2.3 \%$ for the moisture content of wood chips and $5.1 \%$ for the moisture content of bark. To conclude, NIR is the most promising method for use with continuous fuel flow: it has been very well tested, and adjustments to the problems with wood chips have been carried out. In NIR, disturbances such as varying fuel composition are compensated for by using multivariate calibration and partial least squares (PLSs) regression. However, if some parameters change, for example fuel composition, NIR requires new calibration.

James et al. [9] tested the use of microwave beams for measuring moisture content. They showed that microwave attenuation predominantly reflects moisture content, phase change reflects both moisture and density, and details of the depolarization indicate grain angle. The results showed that a microwave system is potentially capable of providing information about moisture. Okamura and Zhang [10] however discovered that moisture content can be determined without any measurements of a sample's weight or thickness or of microwave attenuation by using phase shifts at two microwave frequencies. These findings are in agreement with [9]. The standard error of this method is $2.1 \%$ in the moisture range from $2 \%$ to $30 \%$. Nevertheless, the meth-od is influenced to a minor degree by temperature and grain direction.

Rosenberg et al. [11] carried out a number of measurements to test the use of NMR for the measuring moisture content of spruce and pine. The difference between the NMR instrument and oven-dry measurements varied from $-0.7 \%$ to $+0.4 \%$ with an average of $-0.13 \%$. The results can be considered promising. However, the instrument measurements have to be combined with density measurement, because the instrument detects the number of ther-malized neutrons (counts/s).

A typical indirect method of determining fuel moisture content is to first determine the moisture content of the flue gas, from which the moisture content can be then derived by a mass balance calculation [12]. The only delay of the measurement signal in this setup is due to the transport time of the gas from the furnace to the measurement position. This time delay can be measured in seconds and it thus opens up possibilities of controlling both combustion air and fuel feed.

Fourier-transform infrared (FT-IR) technology is used in one indirect method of determining gas moisture content [13]. Jaakkola et al. [14] investigated the feasibility of a transportable, low resolution FT-IR gas analyzer for analyzing wet extractive stack gas. They reported a relative standard deviation of $4.1 \%$ for moisture content. However, FT-IR-based analysis has been reported to be sensitive to the absolute temperature, pressure, temperature gradients, and particles carried with the gas, complicating measurements carried out directly in the flue gas duct, and this weakens its usability.

A different method for measuring gas moisture content uses a relative-humidity (RH) sensor and was developed by Hermansson et al. [15] with the aim of improving the accuracy level of indirect determination of moisture content of fuel in a biomass furnace. Accurate results were achieved by cooling of the extracted flue gas stream, which increased the RH of the flue gases, before performing the measurements. The results of the tests showed that the method is able to detect variations in moisture content within seconds. However, in order to use this method, new devices, measurements, and calibration are needed.

All of the above methods have their strengths and weaknesses. There is, however, a need for a more costeffective method for measuring fuel moisture because the methods developed so far are too inaccurate and costly for industrial use, especially in a small-scale boiler. A fuel quality soft-sensor that utilizes combustion power and the energy balance of the boiler was developed in [16]. In this method, the boiler model consists of submodels that include the economizer, the evaporator, the primary superheater, the secondary superheater, and the attemperator models. In addition, combustion power is estimated on the basis of the measured oxygen consumption. In [17], the method was improved by replacing the boiler model with a nonlinear secondary superheater mod-el to decrease the estimation delay. In addition, combustion power was estimated by means of a mixed model of convection and radiation heat transfer. 
This study's sensor includes a flue gas temperature model that can use different specific heat capacities for each flue gas component. Moreover, the effect of flue gas recirculation is taken into account in the sensor's flue gas flow and temperature models. The paper is organized as follows: In Section 2, the BioPower 5 CHP plant process is presented. Section 3 presents the fuel moisture soft-sensor. The test results are given in Sections 4 and 5, followed by the conclusions in Section 6.

\section{Description of the process and its control strategy}

In a BioPower 5 CHP plant, the heat used for steam generation is obtained by burning solid biomass fuel consisting of bark, sawdust, and pellets - which is fed into the steam boiler together with combustion air. As a result, combustion heat and flue gases are generated. The heat is then used in the steam-water circulation process.

Fig. 1 shows the boiler part of the BioPower 5 CHP plant. The essential components of the water-steam circuit are an economizer, a drum, an evaporator, and superheaters. Feed water is pumped from a feed water tank into the boiler. First the water is led into the economizer (4), which is heated by the flue gases. This decreases the temperature of the flue gases and improves the efficiency of the boiler.

From the economizer, the heated feed water is led into the drum (5) and along downcomers into the bottom of the evaporator (6) through tubes that surround the boiler. From the evaporator tubes, the heated water and steam return back into the steam drum, where they are separated. The steam rises to the top of the steam drum and flows into the superheaters (7). It heats up further and superheats. The superheated high-pressure steam (8) is led into the steam turbine, where electricity is generated.

In the BioGrate system, the fuel is fed onto the center of a grate from below through a stoker screw. The grate consists of alternate rotating and stationary concentric rings. The rotating rings are hydraulically alternately rotated clockwise and counterclockwise. This design distributes the fuel evenly over the entire grate, with the burning fuel forming an even layer of the required thickness [18].

The moisture content of the wet fuel in the center of the grate evaporates rapidly due to the heat of the surrounding burning fuel and thermal radiation from the brick walls. The gasification and visible combustion of the gases and solid carbon take place as the fuel moves to the periphery of the circular grate. At the edge of the grate, ash finally falls into a water-filled ash basin underneath the grate [18].

The primary air for combustion and the recirculation flue gas are fed from underneath the grate and they penetrate the fuel through slots in the concentric rings. Secondary air is fed directly into the flame above the grate. The air distribution is controlled by dampers and speed-controlled fans [18].

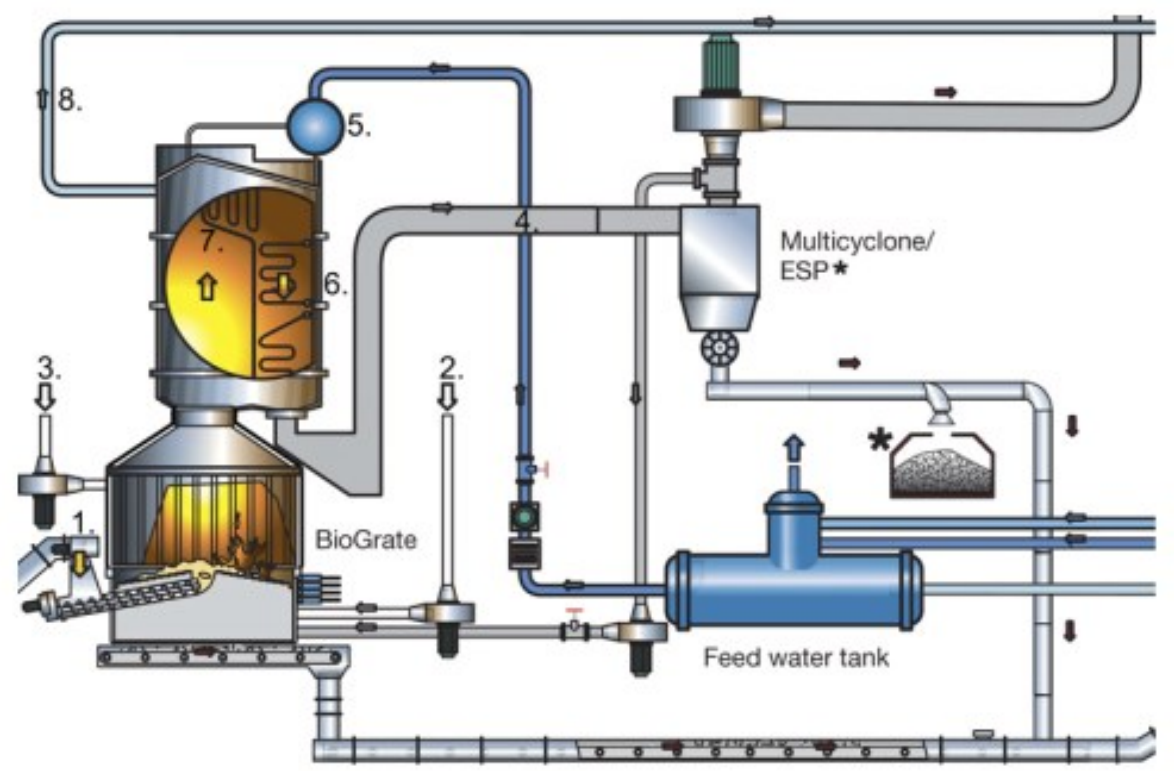

Fig. 1. 1. Fuel, 2. Primary air, 3. Secondary air, 4. Economizer, 5. Drum, 6. Evaporator, 7. Superheaters, 8. Superheated steam. 


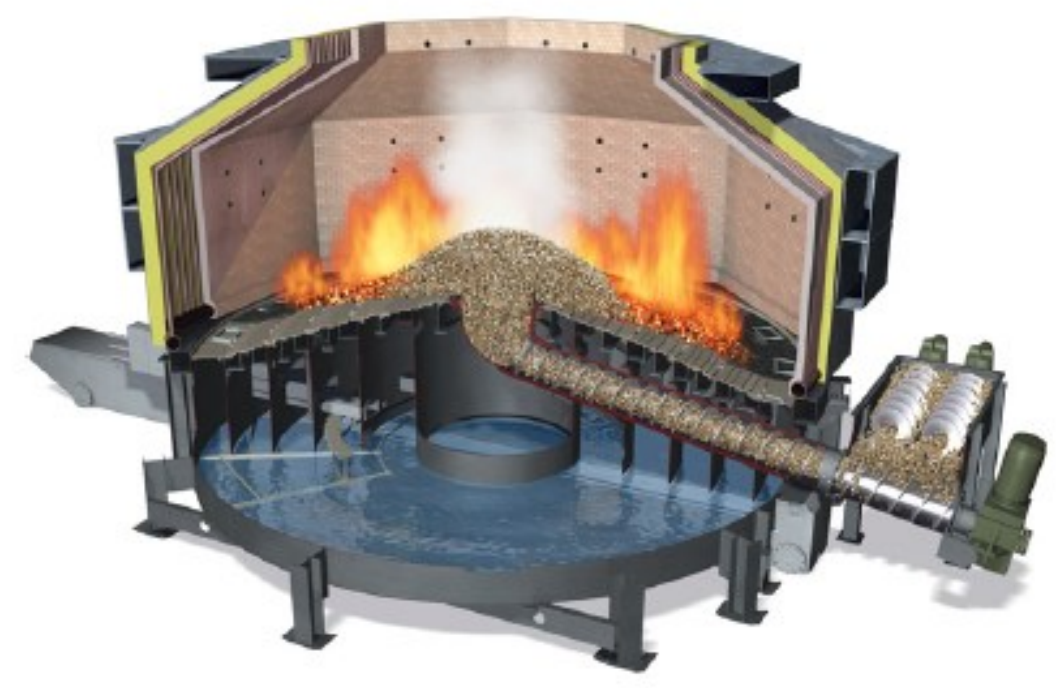

Fig. 2. BioGrate, showing the stoker screw and the water-filled ash basin underneath the grate

\subsection{Control strategy of the BioGrate process}

The main aim of the control strategy of the BioGrate process is to produce a desired amount of energy by keeping the drum pressure constant. At the highest level of the control strategy, the drum pressure control defines the power of the boiler. At a lower level, the necessary boiler power is produced by controlling the amount of combustion air and fuel.

The primary air flow is controlled by the set point that comes from the pressure control. The fuel feed is controlled to track the primary air flow measurement. The necessary amount of primary air and secondary air for diverse fuel and power levels are specified by air curves that have been calculated in the boiler design phase. The flue gas oxygen controller acts as a master controller while the set point of the secondary air controller is adjusted to provide the desired amount of excess air for the combustion.

\subsection{Fuel composition and fuel quality}

The elemental composition and quality of solid fuel have a strong effect on its heat value. This means that fuel quality plays a key role when designing the control strategy of a BioPower plant and ensuring its optimal operation. All biomass fuels contain are carbon $(\mathrm{C})$, hydrogen $(\mathrm{H})$, oxygen $(\mathrm{O})$, and nitrogen $(\mathrm{N})$. In addition, biomass fuels contain substances from soil, such as water, minerals, rock materials, and sulfur (S). The actual combustible components of fuels are carbon, hydrogen, and sulfur. Sulfur is an unwanted component because its combustion produces harmful sulfur dioxide. Some of the nitrogen reacts with oxygen, forming harmful nitrogen oxides. If fuel contains moisture, this evaporates when the fuel is burned, but this evaporation requires energy, which is absorbed from the heat of the fuels combustion and decreases the fuels heat value. Table 1 lists the elemental composition and typical moisture content of wood fuels burned in the BioPower 5 CHP plant.

Table 1

The composition of wood fuels burned in the BioPower 5 CHP plant

\begin{tabular}{lllllll}
\hline Fuel & \multicolumn{3}{l}{ Dry content (\%) } & & & Moisture (\%) \\
\cline { 2 - 6 } & $w_{C}$ & $w_{H}$ & $w_{O}$ & $w_{N}$ & Ash & w \\
\hline Pine & 54.5 & 5.9 & 37.6 & 0.3 & 1.7 & 60 \\
Spruce & 50.6 & 5.9 & 40.2 & 0.5 & 2.8 & 60 \\
Wood mix & 50.4 & 6.2 & 42.5 & 0.5 & 0.4 & 50 \\
\hline
\end{tabular}

The heat value of a fuel can be determined by using the equation that has been derived from the heat values of the fuel's combustible components when they combine with oxygen [19]. The effective heat value of a dry fuel is 
$\left.q_{w f}=0.348 \cdot w_{C}+0.938 \cdot w_{H}+0.105 \cdot w_{S}+0.063 \cdot w_{N}-0.108 \cdot w_{O}[\mathrm{M}] / \mathrm{kg}\right]$

where $w_{C}$ is the mass fraction of carbon in the fuel (\%), $w_{H}$ is the mass fraction of hydrogen in the fuel (\%), $w_{S}$ is the mass fraction of sulfur in the fuel (\%), $w_{N}$ is the mass fraction of nitrogen in the fuel (\%), and $w_{O}$ the mass fraction of oxygen in the fuel (\%). The effective heat value of a wet fuel is obtained using the equation

$q_{f}=q_{w f} \cdot(1-w / 100)-0.0244 \cdot w[\mathrm{MJ} / \mathrm{kg}]$

where $w$ is the moisture content of the wet fuel (\%). In order to use Eq. (2), the composition of the fuel has to be known.

\section{Fuel moisture soft-sensor}

This study's fuel moisture soft-sensor was based on combustion power estimation and a dynamic model of the secondary superheater. Firstly, fuel flow $\widehat{m}_{f}(w)$ was estimated using the combustion model as shown in Fig. 3. Secondly, the estimated fuel flow $\widehat{m}_{f}(w)$ was used to calculate the flue gas flow $m_{f g}$ and flue gas temperature $T_{f g}$. Thirdly, the flue gas flow $\widehat{m}_{f g}$ and the flue gas temperature $\widehat{T}_{f g}$ were used together with the input enthalpy $h_{1}$ and the steam flow $m_{1}$ to predict the output enthalpy $\hat{h}_{2}(i)$ of the secondary superheater model. Finally, the unknown fuel moisture disturbance w could be estimated with the least squares method.

$\min J(w)=\sum_{i=0}^{N}\left|h_{2}(i)-\hat{h}_{2}(i)\right|^{2}$

where $N$ is the moving window, $h_{2}$ is the measured output enthalpy of the secondary superheater $(\mathrm{MJ} / \mathrm{kg})$, and $\hat{h}_{2}$ the estimated output enthalpy of the secondary superheater $(\mathrm{MJ} / \mathrm{kg})$. The details of the models are presented in the Sections 3.1 and 3.2.

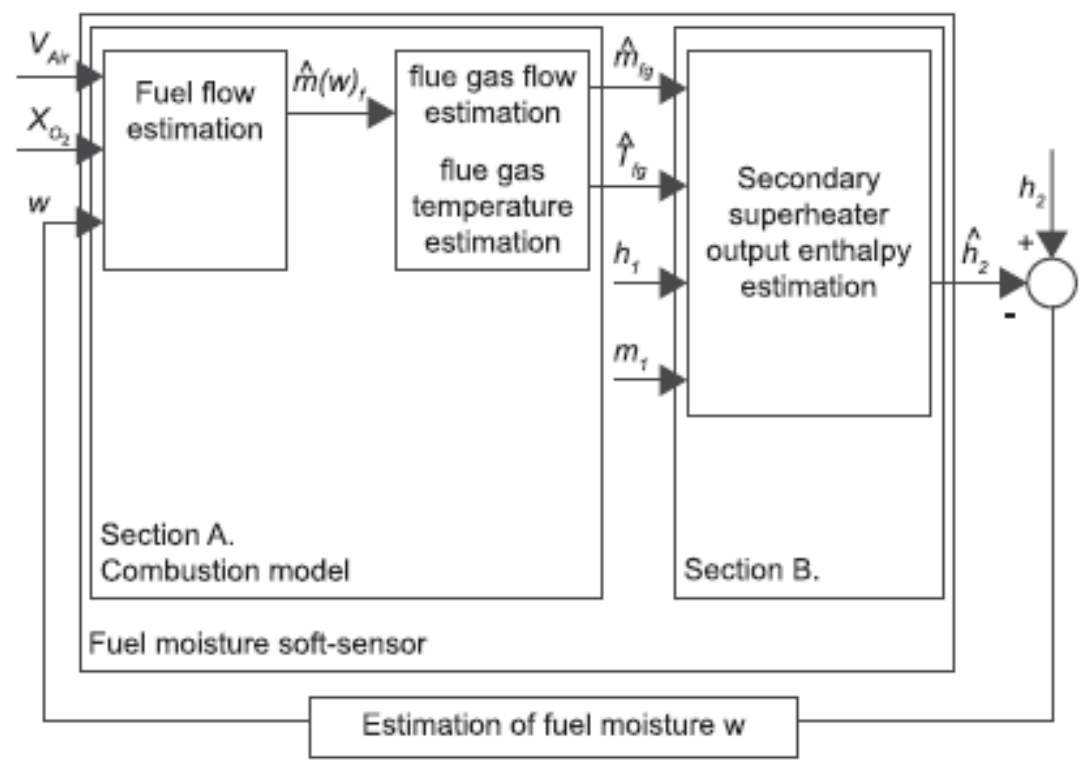

Fig. 3. The fuel moisture soft-sensor

\subsection{Estimations of fuel flow, flue gas flow, and temperature}

Combustion reactions in BioPower plants occur mainly between carbon and oxygen. Oxygen consumption and flue gas composition are therefore good measures of heat generation in such a plant's furnace [20]. The amount of oxygen needed for fuel combustion can be determined from the reaction equations. Table 2 presents the moles of the fuel components per mass unit of the fuel. In summary, based on the amount of oxygen needed for completely combusting the different fuel components, minus the amount of oxygen in the fuel, the theoretical amount of oxygen needed to completely burn one kilogram of fuel is 
$N_{O_{2}}^{g}=n_{C}+0.5 \cdot n_{H_{2}}+n_{S}-n_{O_{2}}[\mathrm{~mol} / \mathrm{kg}]$

Flue gases contain, in addition to combustion products, nitrogen $\mathrm{N}$ that comes with the combustion air. Flue gas calculations therefore include 3.76 times more nitrogen than the amount of oxygen necessary for complete combustion. Incombustible components, for example, water are included in the equations as such. The flue gas flow for one kilogram of fuel is thus

$N_{f g}=n_{C}+n_{H_{2}}+n_{S}+3.76 \cdot N_{O_{2}}^{g}+n_{N_{2}}+n_{H_{2} O}[\mathrm{~mol} / \mathrm{kg}]$

The estimated amount of fuel burned can be calculated as follows [16]

$m_{f}(w)=\frac{\left(0.21-\frac{X_{O_{2}}}{100}\right) n_{\text {Air }}}{N_{O_{2}}^{g}+\frac{X_{O_{2}}}{100}\left(N_{f g}-4.76 \cdot N_{O_{2}}^{g}\right)}[\mathrm{kg} / \mathrm{s}]$

where $X_{O_{2}}(t+\tau)$ is the oxygen content of the flue gas (\%), and $n_{\text {Air }}$ the total air flow (mol/s). Therefore, the flue gas flow is

$m_{f g}=m_{f}(w) \cdot N_{f g}[\mathrm{~kg} / \mathrm{s}]$

and the flue gas temperature is

$T_{f g}=\left(q_{f}+0.21\left(F_{A i r} /\left(22.41 \cdot 10^{-3} \cdot m_{f}\right) C_{O_{2}}+0.79\left(F_{A i r} /\left(22.41 \cdot 10^{-3} \cdot m_{f}\right) C_{N_{2}}\right) /\right.\right.$

$\left(n_{C} C_{C O_{2}}+n_{S} C_{S_{2}}+\left(n_{\mathrm{H}_{2} \mathrm{O}}+n_{\mathrm{H}_{2}}\right) C_{\mathrm{H}_{2} \mathrm{O}}+\left(3.76 \cdot N_{\mathrm{O}_{2}}^{g}+n_{N_{2}}\right) C_{N_{2}}+0.21 \cdot N_{E x A i r} C_{O_{2}}+0.79\right.$.

$N_{\text {ExAir }} C_{N_{2}}$ ) [ $\left.{ }^{\circ} \mathrm{C}\right]$

where $F_{\text {Air }}$ is the total air flow $\left(\mathrm{m}^{3} / \mathrm{s}\right), C_{i}$ the specific heat capacity $i(\mathrm{~J} / \mathrm{mol} \mathrm{T})$, and the $N_{\text {ExAir }}$ excess air $(\mathrm{mol} / \mathrm{kg})$.

Table 2

Moles of the fuel components per mass unit of the fuel

\begin{tabular}{llll}
\hline Comp. & Mass fraction $(\%)$ & $M_{i}(\mathrm{~g} / \mathrm{mol})$ & $n_{i}(\mathrm{~mol} / \mathrm{kg})$ \\
\hline $\mathrm{C}$ & $w_{C}(1-w / 100)$ & 12.011 & $w_{C}(1-w / 100) 10 / M_{C}$ \\
$\mathrm{H}$ & $w_{H}(1-w / 100)$ & 2.0158 & $w_{H}(1-w / 100) 10 / M_{H}$ \\
$\mathrm{~S}$ & $w_{S}(1-w / 100)$ & 32.06 & $w_{S}(1-w / 100) 10 / M_{S}$ \\
$\mathrm{O}$ & $w_{O}(1-w / 100)$ & 31.9988 & $w_{O}(1-w / 100) 10 / M_{O}$ \\
$\mathrm{~N}$ & $w_{N}(1-w / 100)$ & 28.01348 & $w_{N}(1-w / 100) 10 / M_{N}$ \\
Water & $w$ & 18.0152 & $10 / M_{w}$ \\
\hline
\end{tabular}

\subsection{Secondary superheater model}

The behavior of the boiler can be described by using global mass and energy balances. The heat released by the combustion of fuel is transferred to the water and steam in the boiler, where each section can be considered a thermal system [21]. In this study, fuel moisture content was estimated using a dynamic model of the secondary superheater. The energy balance of the boiler section and the temperature of the metal walls were taken into consideration separately to improve the model's accuracy.

The heat transfer from the flue gas to the metal walls in the presence of mixed convection and radiation heat transfer is $[22,23]$

$\left.Q_{w}=\alpha_{w} m_{f g}^{0.65}\left(\left(T_{f g}-\alpha_{f 0} * T_{f 0}\right)-T_{w}\right)+k_{w}\left(T_{f g} \alpha_{f 0} * T_{f g}\right)^{4}-T_{w}^{4}\right)[\mathrm{MJ} / \mathrm{s}]$

where $\alpha_{w}$ is the convection heat transfer, $\alpha_{f 0}$ is the correction coefficient, $T_{f 0}$ is the outlet flue gas temperature $\left({ }^{\circ} \mathrm{C}\right), T_{w}$ is the temperature of the metal walls $\left({ }^{\circ} \mathrm{C}\right)$, and $k_{w}$ is the radiation heat transfer coefficient. The energy balance for the tube walls is 
$\frac{d T_{w}}{d t}=\frac{1}{m_{t} C_{p}}\left(Q_{w}-Q_{t}\right)[\mathrm{K} / \mathrm{s}]$

where $m_{t}$ is the mass of the metal tubes $(\mathrm{kg})$, and $C_{p}$ is the specific heat of the metal $(\mathrm{MJ} / \mathrm{kg} \mathrm{K})$. The heat transfer from the metal walls to the steam/water in the presence of convection heat transfer (superheaters) is

$Q_{t}=\alpha_{c} m_{2}^{0.8}\left(T_{w}-T\right)[\mathrm{MJ} / \mathrm{s}]$

where $\alpha_{c}$ is the convection heat transfer coefficient.

$T=\left(T_{1}+T_{2}\right) / 2\left[{ }^{\circ} \mathrm{C}\right]$

where $T_{1}$ is the input steam/water temperature $\left({ }^{\circ} \mathrm{C}\right)$ and $\mathrm{T} 2$ the output steam/water temperature $\left({ }^{\circ} \mathrm{C}\right)$. Finally the energy balance of the output steam enthalpy is

$\frac{d h_{2}}{d t}=\frac{1}{Q V}\left(Q_{t}+m_{1} h_{1}-m_{2} h_{2}\right)[\mathrm{MJ} /(\mathrm{s} \mathrm{kg})]$

where $h_{2}$ is the specific output enthalpy of the steam/water $(\mathrm{MJ} / \mathrm{kg}), Q$ is the specific density of the steam $/$ water $\left(\mathrm{kg} / \mathrm{m}^{3}\right), V$ is the volume of the steam $/$ water $\left(\mathrm{m}^{3}\right), m_{1}$ is the input steam/water flow $(\mathrm{kg} / \mathrm{s}), h_{1}$ is the specific input enthalpy of the steam $/$ water $(\mathrm{MJ} / \mathrm{kg})$, and $m_{2}$ is the output steam $/$ water flow $(\mathrm{kg} / \mathrm{s})$.

\section{Description of the testing environment}

All the experiments were conducted at the BioPower 5 CHP plant, which produces $13.5 \mathrm{MW}$ heat and 2.9MW electricity. The plant utilizes BioGrate combustion technology as presented in Fig. 2. This technology has been developed for very wet biomass fuels with a moisture content as high as $65 \%$.

Two fuels were used to test the moisture soft-sensor: spruce bark with an average moisture content of 54\% and a typical bark composition (carbon $51 \%$, hydrogen $6.2 \%$, nitrogen $<0.2 \%$, sulfur $<0.2 \%$, and ash $0.5 \%$ ) as shown in Table 3, and dry woodchips (spruce) with a moisture content of $20 \%$.

Table 3

The fuel composition of the sampled fuel moisture

\begin{tabular}{lllllll}
\hline Samples & $w_{C}$ & $w_{H}$ & $w_{S}$ & $w_{N}$ & Ash & $\mathrm{MJ} / \mathrm{kg}$ \\
\hline $5-11$ & 51.4 & 6.0 & 0.2 & $<0.3$ & 2.8 & 18.91 \\
$20-30$ & 51.0 & 6.2 & $<0.2$ & $<0.2$ & 0.5 & 18.82 \\
\hline
\end{tabular}

To ensure that the moisture content changed stepwise, dry biomass was fed by means of the wheel loader onto the moving chain conveyor between portions of wet fuel through the extra feeding box. The arrangement for the sampling of the fuel feed is shown in Fig. 4. The samples were taken every 5 min from fuel dropping from the fuel silo just before the stoker screw. The measurement arrangement for the Servomex 2500 FT-IR analyzer is shown in Fig. 5. The flue gas was extracted from the flue gas duct and led into the analyzer. Samples were analyzed every second.

The calculations presented in Section 3 were performed to obtain the current rate of water evaporation (fuel moisture softsensor value) and the current rate of thermal decomposition of the biomass based on measurements of current air mass flows, current flue gas oxygen content, current steam temperatures, current steam flow and current steam pressure, as well as the results of the dry fuel analysis. All values were recorded every second. The following assumptions were made: Excess air was used to enable the complete combustion of fuel, and the composition of the dry fuel was constant, which is also supported by Tables 3 and 4 . This means that the combustion power estimation method is valid. 


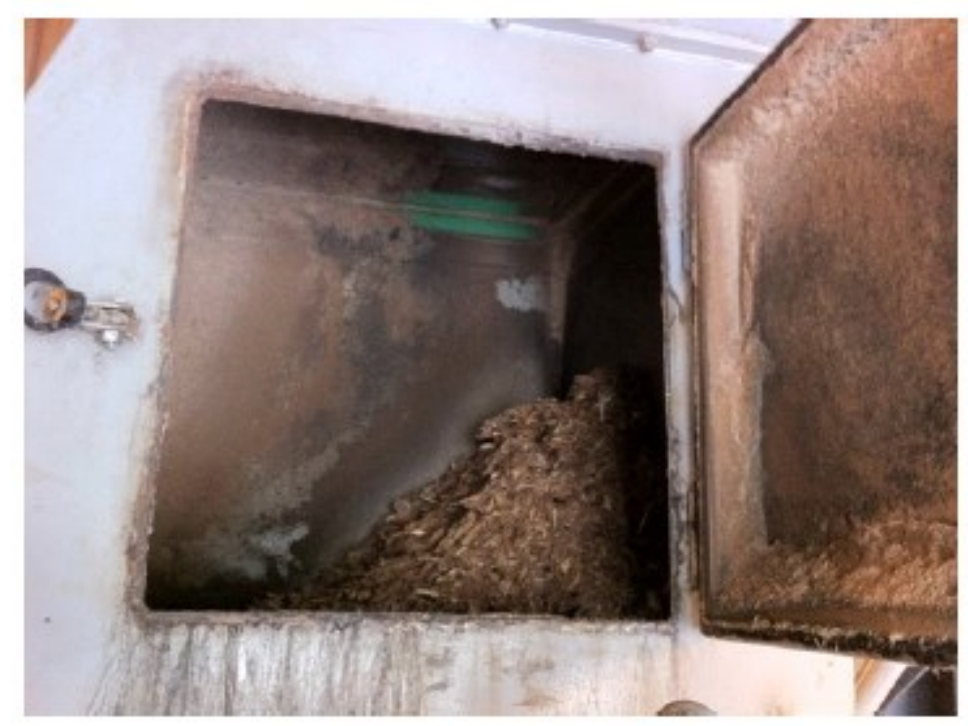

Fig. 4. Measurement set-up for fuel feed sampling

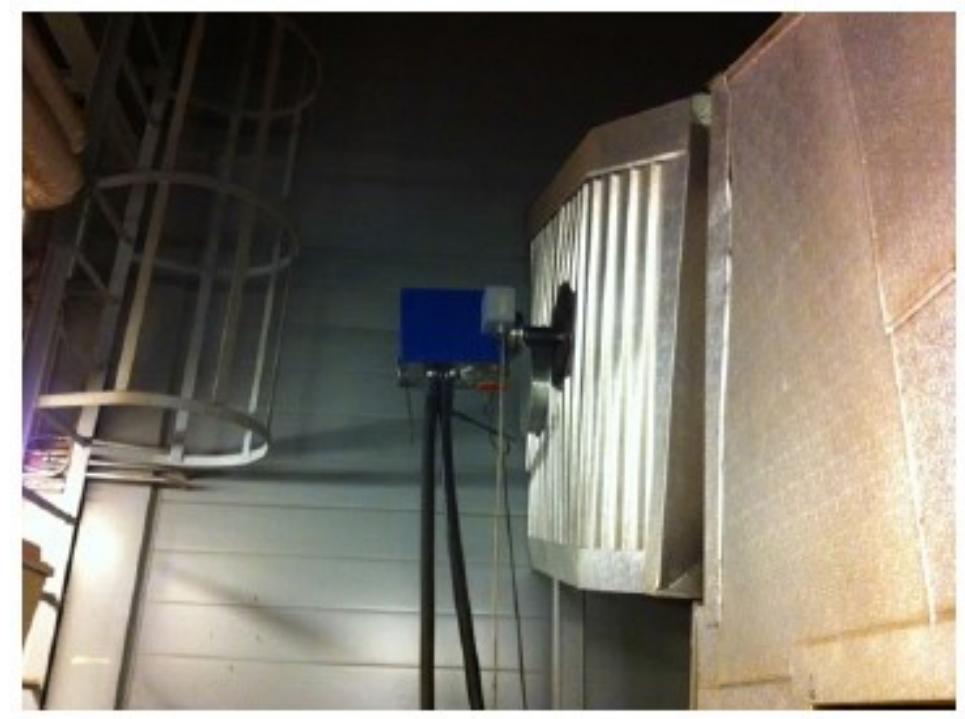

Fig. 5. Measurement set-up of the FT-IR analyzer in the flue gas duct

\section{Test results of the fuel moisture soft-sensor}

Three experiments were conducted to validate the fuel moisture soft sensor. Dry fuel was gradually increased in each experiment in order to see the effect of moisture on the sensor and the combustion process. In the first test, $5 \mathrm{~m} 3$ of dry biomass was fed onto the chain conveyor at 13:13. The results of the test are shown in Figs. 6-8. The top illustration of Fig. 6 shows the values calculated by the fuel moisture softsensor (thick line), the sampled fuel moisture (stars), and the fuel moisture calculated from the FT-IR measurements (thin line). There was a delay of about $20 \mathrm{~min}$ between when the fuel moisture samples were taken before the stoker screw - as shown on the right side of Fig. 2 - and when the moisture content of the wet fuel in the center of the grate was estimated by the fuel moisture soft sensor and measured by the FTIR analyzer. Therefore, the sampled fuel moisture was not directly comparable to the estimations of the fuel moisture soft sensor and the measurements of the FT-IR analyzer measurements, but it gave an accurate measure of the moisture content in the fuel feed.

The temperature after the secondary superheater and the drum pressure increased due to the dry fuel and the resulting greater combustion power. A mix of dry and wetter fuel remained in the center of the grate. As a result, the fuel moisture soft sensor and the FT-IR analyzer indicated higher moisture values, and these also had less of an impact on the secondary superheater temperature and the drum pressure. Primary air was used to control the boiler's power. Therefore, primary air decreases due to control action that reduced the primary 
air flow corresponded to increases in drum pressure. As a result, the drum pressure and the secondary superheater temperature decreased when the superheated steam flow was kept at a high value. In addition, drum pressure, superheated steam temperature, and steam flow can suddenly increase or decrease due to steam demand changes after the turbine. Furthermore, the flue gas oxygen content was kept at $4 \%$ using secondary air. This meant that secondary air varied mainly independently from primary air and other variables. The temperature increases on grate 10 were due to dry fuel that moved to the periphery of the grate. As a result, the furnace temperature increased. As a consequence, the flue gas circulation fan speed increased when to control action lowered the temperature.

\section{Table 4}

The sampled fuel moisture content

\begin{tabular}{|c|c|c|c|}
\hline Sample & Test & Time & Moisture (\%) \\
\hline 1 & Preparation & $8: 00$ & 56.1 \\
\hline 2 & Preparation & $8: 30$ & 54.9 \\
\hline 3 & Preparation & 9:00 & 53.4 \\
\hline 4 & Preparation & $9: 30$ & 54.4 \\
\hline 5 & Test 0 & $10: 00$ & 54.8 \\
\hline 6 & Test 0 & $10: 20$ & 54.7 \\
\hline 7 & Test 0 & $10: 40$ & 54.4 \\
\hline 8 & Test 0 & $11: 00$ & 54.4 \\
\hline 9 & Test 0 & $11: 20$ & 54.4 \\
\hline 10 & Test 0 & $11: 40$ & 54.2 \\
\hline 11 & Test 0 & $12: 00$ & 54.9 \\
\hline 12 & Test 1 & $13: 10$ & 23.8 \\
\hline 13 & Test 1 & $13: 15$ & 29.1 \\
\hline 14 & Test 1 & $13: 20$ & 52.8 \\
\hline 15 & Test 2 & $15: 14$ & 20.7 \\
\hline 16 & Test 2 & $15: 20$ & 23.6 \\
\hline 17 & Test 2 & $15: 25$ & 23.3 \\
\hline 18 & Test 2 & $15: 30$ & 22.9 \\
\hline 19 & Test 2 & $15: 35$ & 49.7 \\
\hline 20 & Test 3 & $9: 59$ & 34.5 \\
\hline 21 & Test 3 & $10: 05$ & 21.2 \\
\hline 22 & Test 3 & $10: 10$ & 31.7 \\
\hline 23 & Test 3 & $10: 15$ & 29.2 \\
\hline 24 & Test 3 & $10: 20$ & 36.2 \\
\hline 25 & Test 3 & $10: 25$ & 26.7 \\
\hline 26 & Test 3 & $10: 30$ & 21.3 \\
\hline 27 & Test 3 & $10: 35$ & 21.9 \\
\hline 28 & Test 3 & $10: 40$ & 24.9 \\
\hline 29 & Test 3 & $10: 45$ & 24.1 \\
\hline 30 & Test 3 & $10: 50$ & 22.0 \\
\hline
\end{tabular}

In the second test, $10 \mathrm{~m} 3$ of dry biomass was fed onto the chain conveyor at 15:18. The results of the test are illustrated in Figs. 9-11. Since the amount of fuel was twice that used in the first test, the temperature after the secondary superheater and the drum pressure first increased but then decreased rapidly due to control action that decreased the primary air. As a result of the greater amount of dry fuel in the furnace, the temperature also increased on grate rings 2 and 4. Furthermore, the temperature after the secondary superheater increased again and thus caused fluctuations in the process variables.

Finally, in the third test, $25 \mathrm{~m} 3$ of dry biomass was fed onto the chain conveyor at 10:03. The results of the test are shown in Figs. 12-14. Similarly to the results of the second test, the temperature after the secondary superheater and the drum pressure first increased but then decreased rapidly due to control action that decreased the primary air. The temperature increases on the grate rings 2,4 , and 10 . Moreover, the temperature after the secondary superheater and the drum pressure again increased and thus caused fluctuation, though for a longer time than in the second test. 

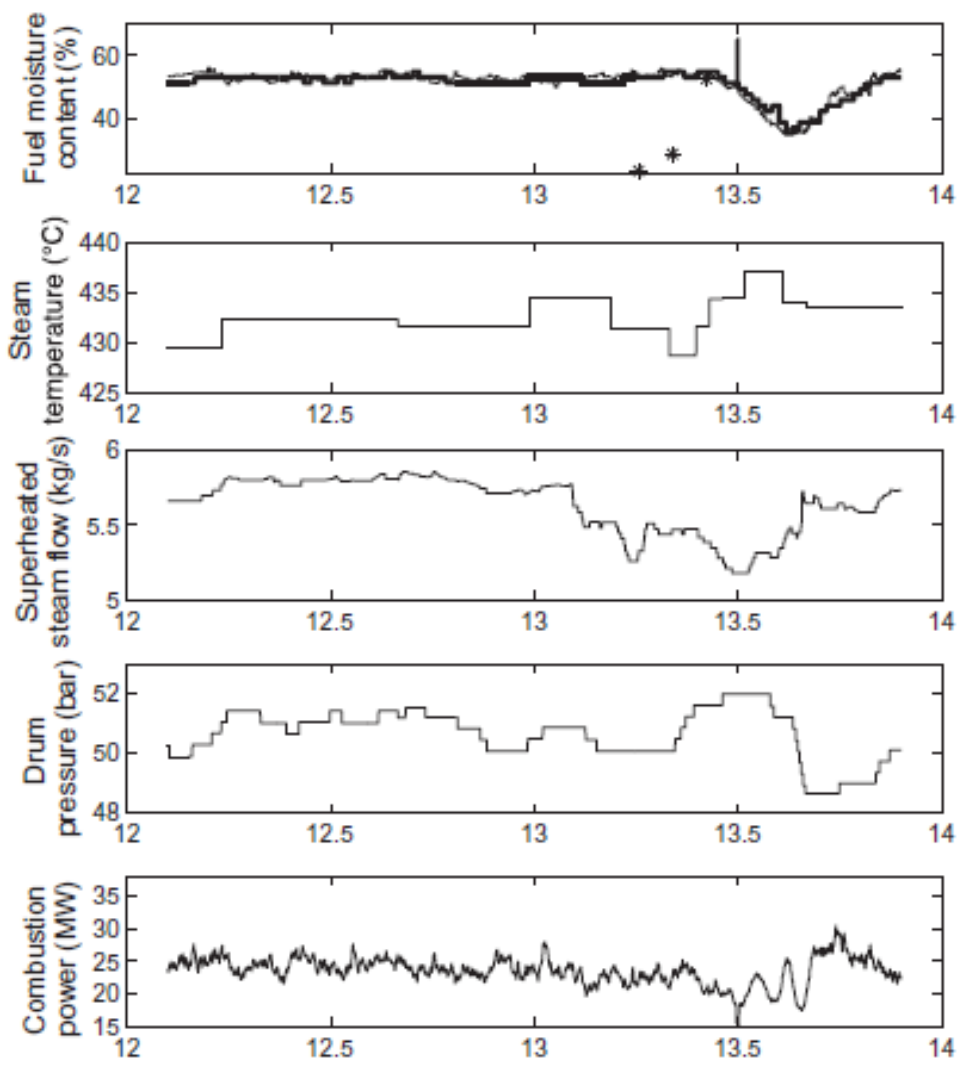

Fig. 6. Boiler measurements during the first test, including measurements of superheated steam temperature, superheated steam flow, drum pressure, and combustion power reactions to changes in the moisture content of the fuel flow. The top illustration shows the values calculated by the fuel moisture soft-sensor (thick line), the sampled fuel moisture (stars), and the fuel moisture calculated from the FT-IR measurement (thin line) for comparison.
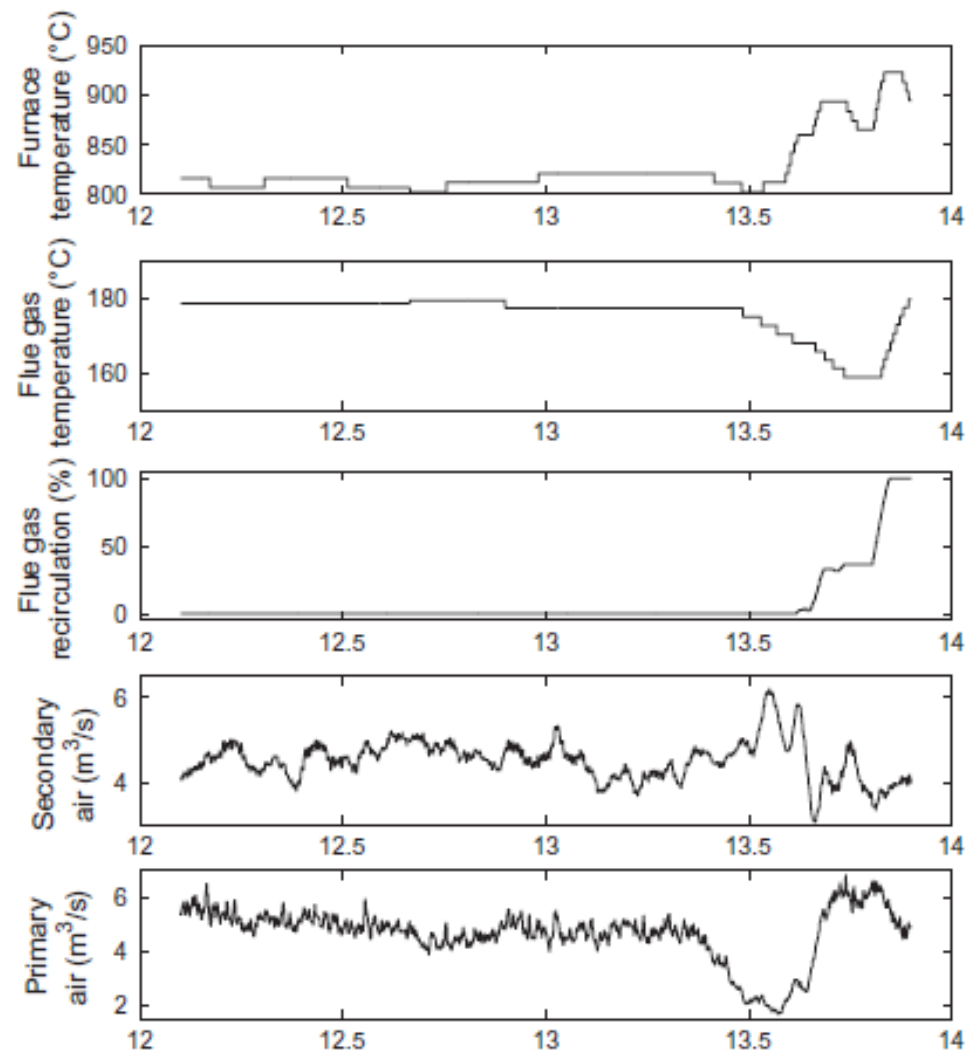

Fig. 7. Boiler measurements during the first test, including furnace temperature, flue gas temperature, and changes in flue gas fan speed, secondary air flow, and primary air flow as reactions to changes in the moisture content of the fuel flow. 

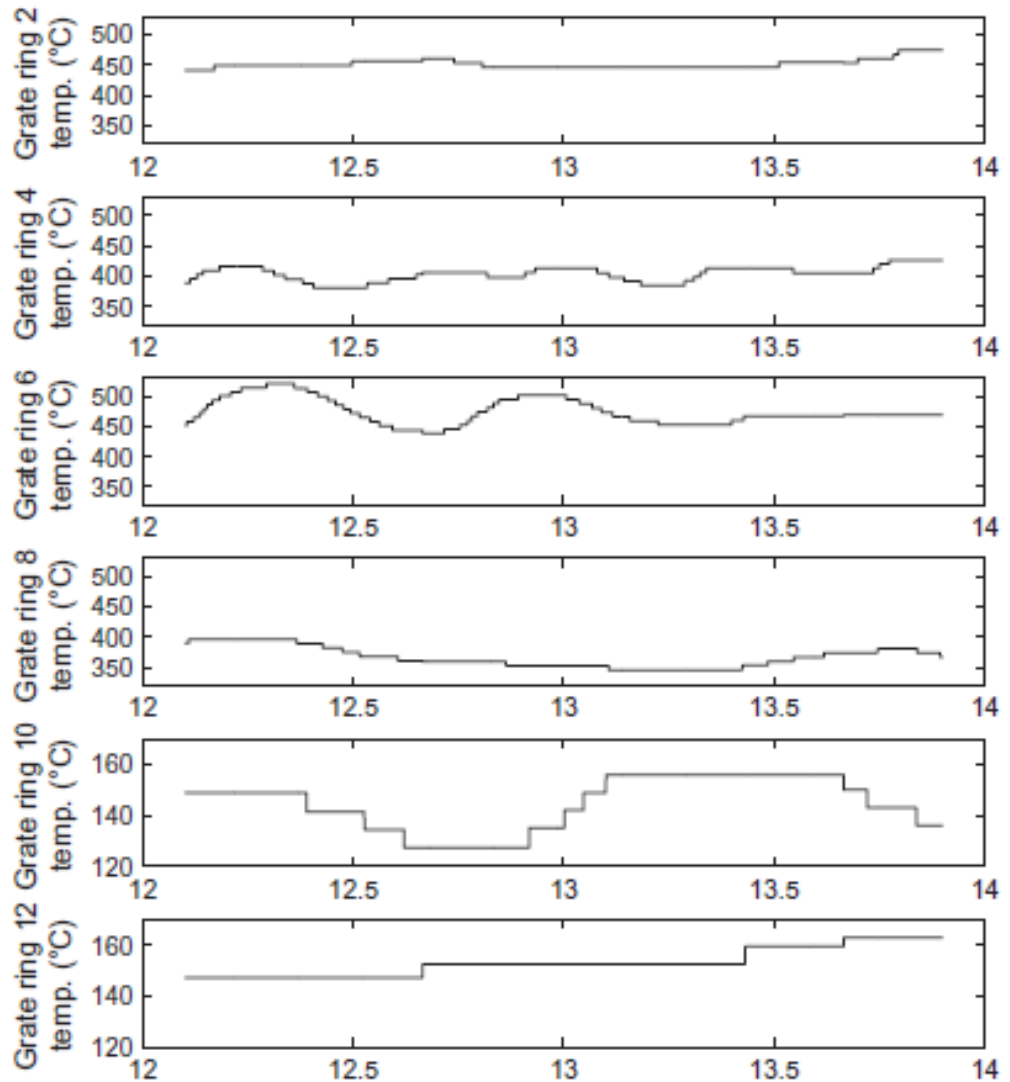

Fig. 8. Grate temperatures during the first test. The grate rings are numbered from the center (grate ring 2 ) to the edge of the grate (grate ring 12)
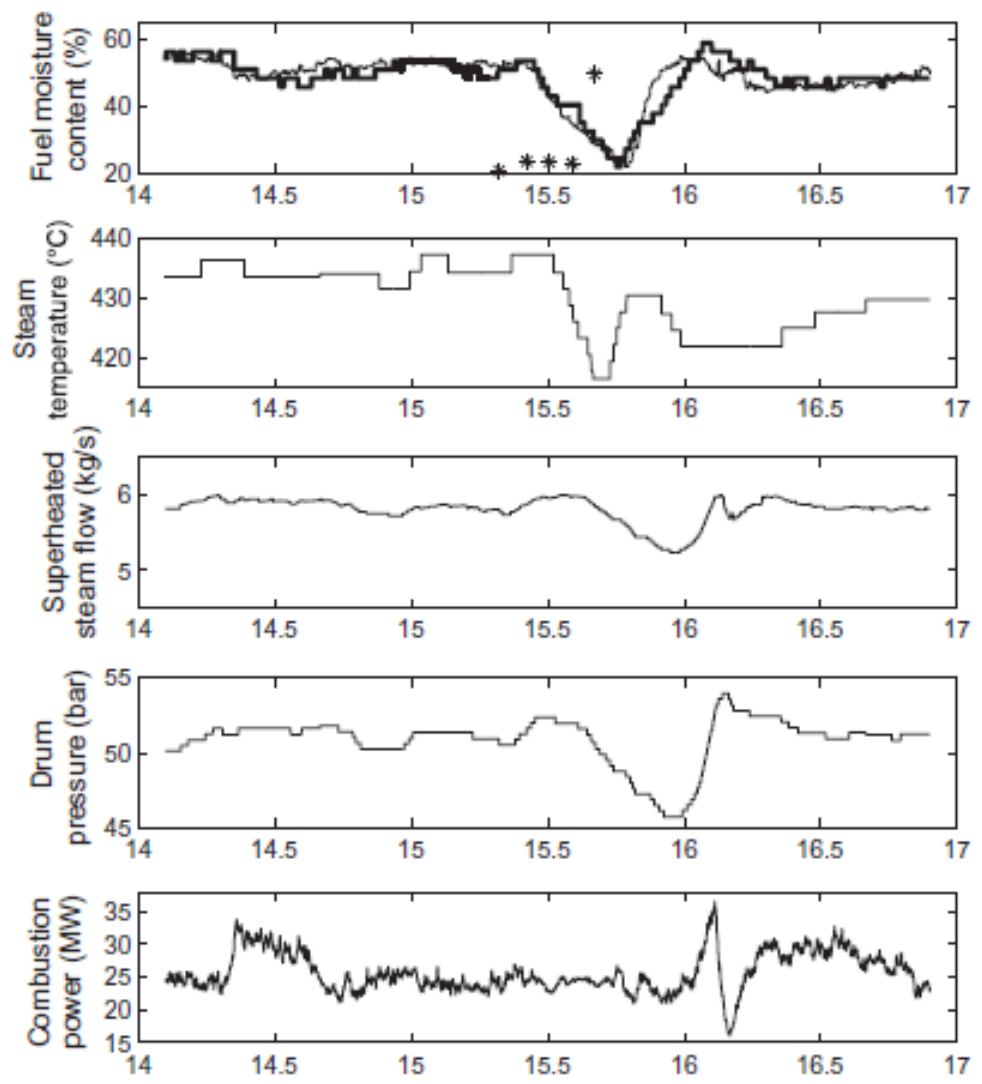

Fig. 9. Boiler measurements during the second test, including measurements of superheated steam temperature, superheated steam flow, drum pressure, and combustion power reactions to changes in the moisture content of the fuel flow. The top illustration shows the values calculated by the fuel moisture soft-sensor (thick line), the sampled fuel moisture (stars), and the fuel moisture calculated from the FT-IR measurement (thin line) for comparison. 

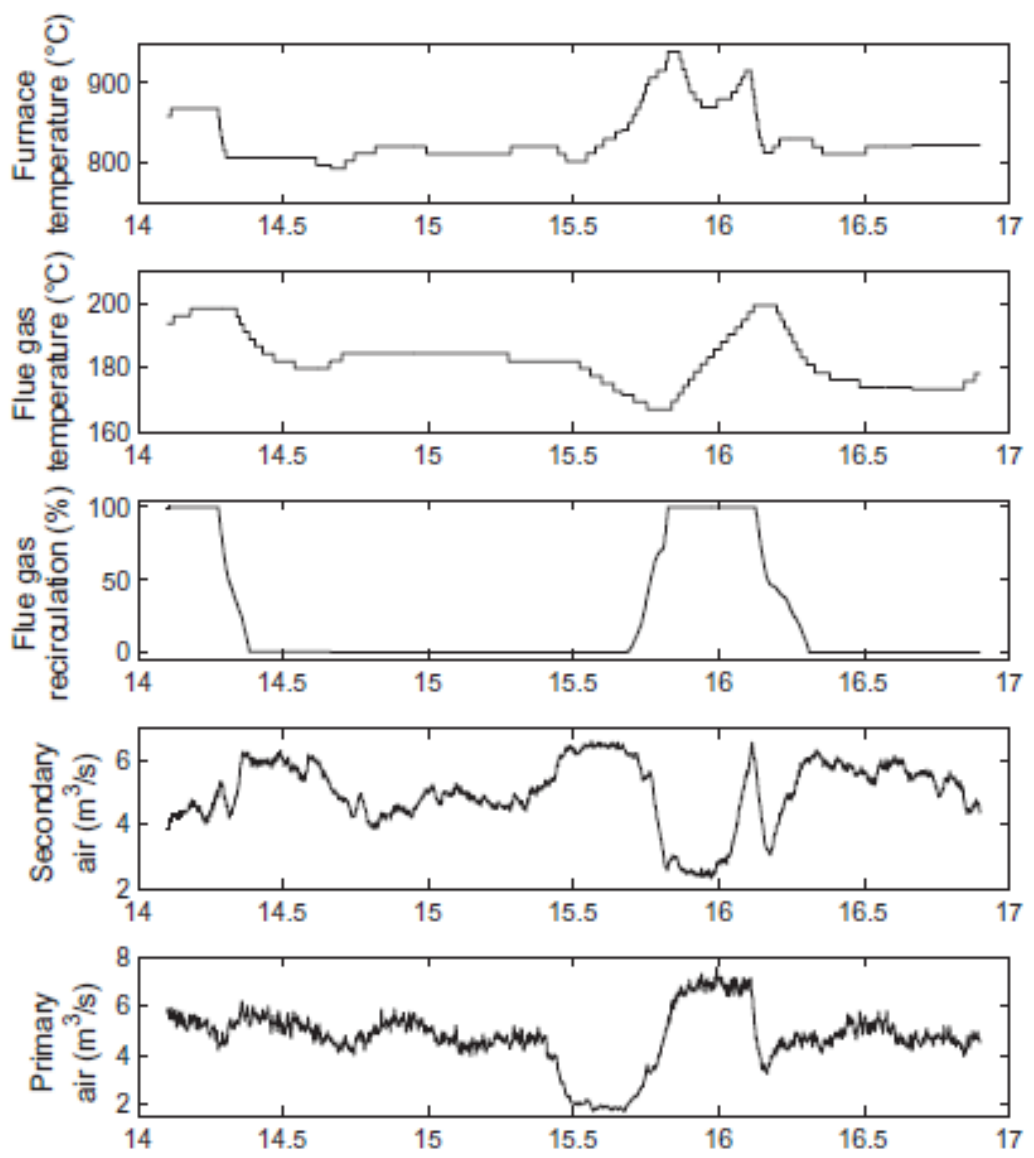

Fig. 10. Boiler measurements during the second test, including furnace temperature, flue gas temperature, and changes in flue gas fan speed, secondary air flow, and primary air flow as reactions to changes in the moisture content of the fuel flow.
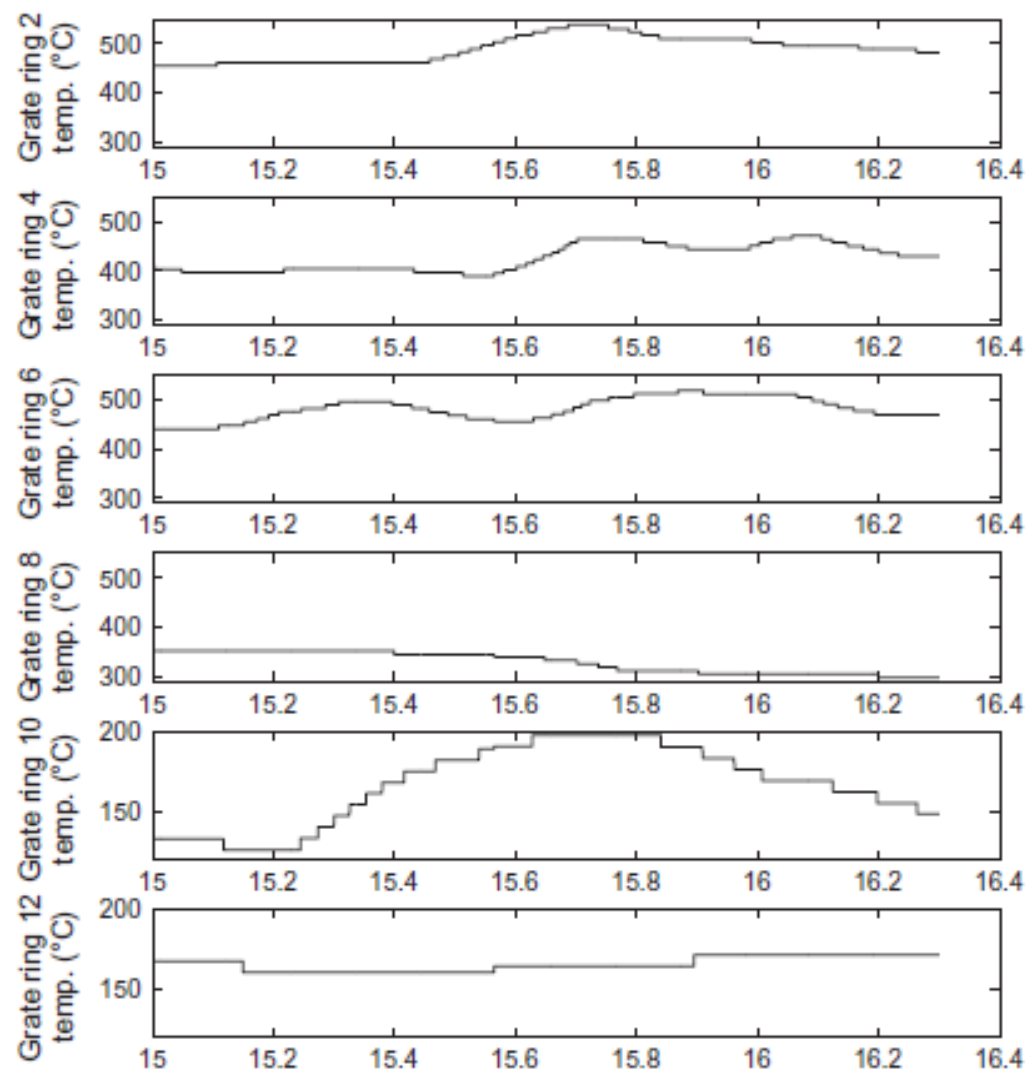

Fig. 11. Grate temperatures during the second test. The grate rings are numbered from the center (grate ring 2) to the edge of the grate (grate ring 12). 

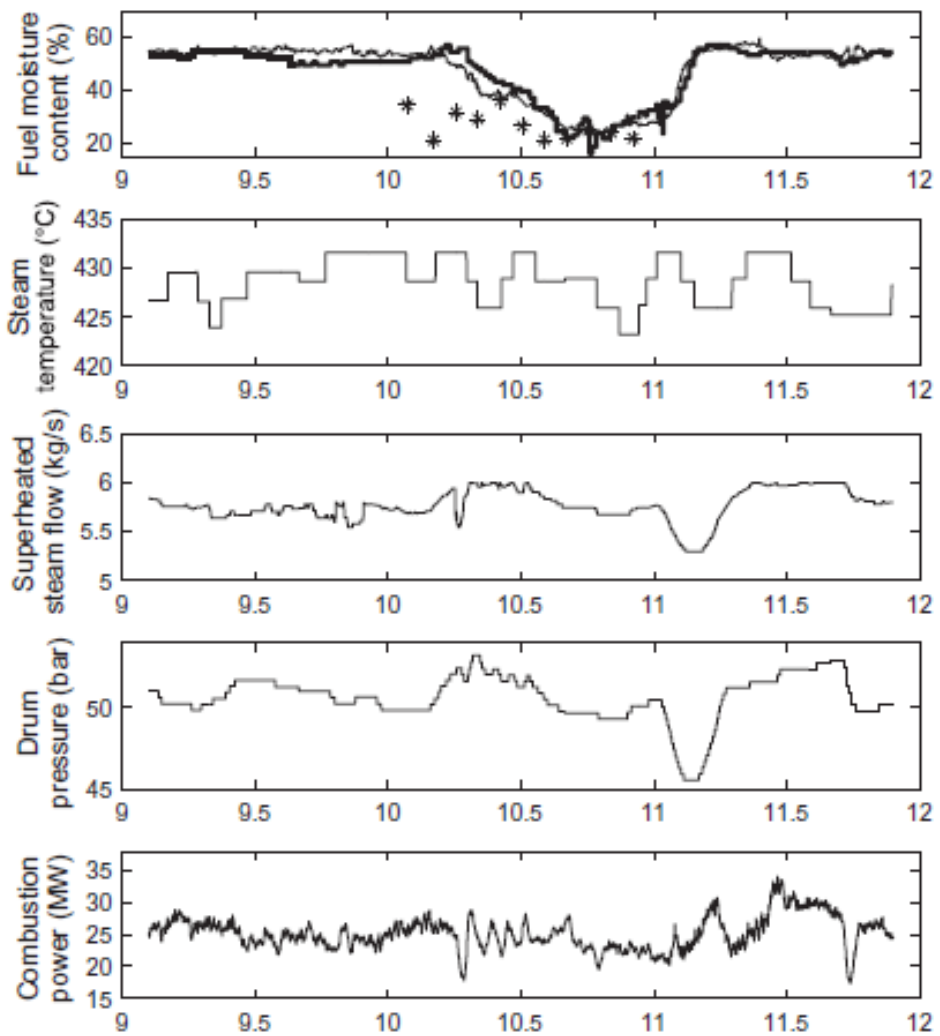

Fig. 12. Boiler measurements during the third test, including measurements of superheated steam temperature, superheated steam flow, drum pressure, and combustion power reactions to changes in the moisture content of the fuel flow. The top illustration shows the values calculated by the fuel moisture soft-sensor (thick line), the sampled fuel moisture (stars), and the fuel moisture calculated from the FT-IR measurement (thin line) for comparison.
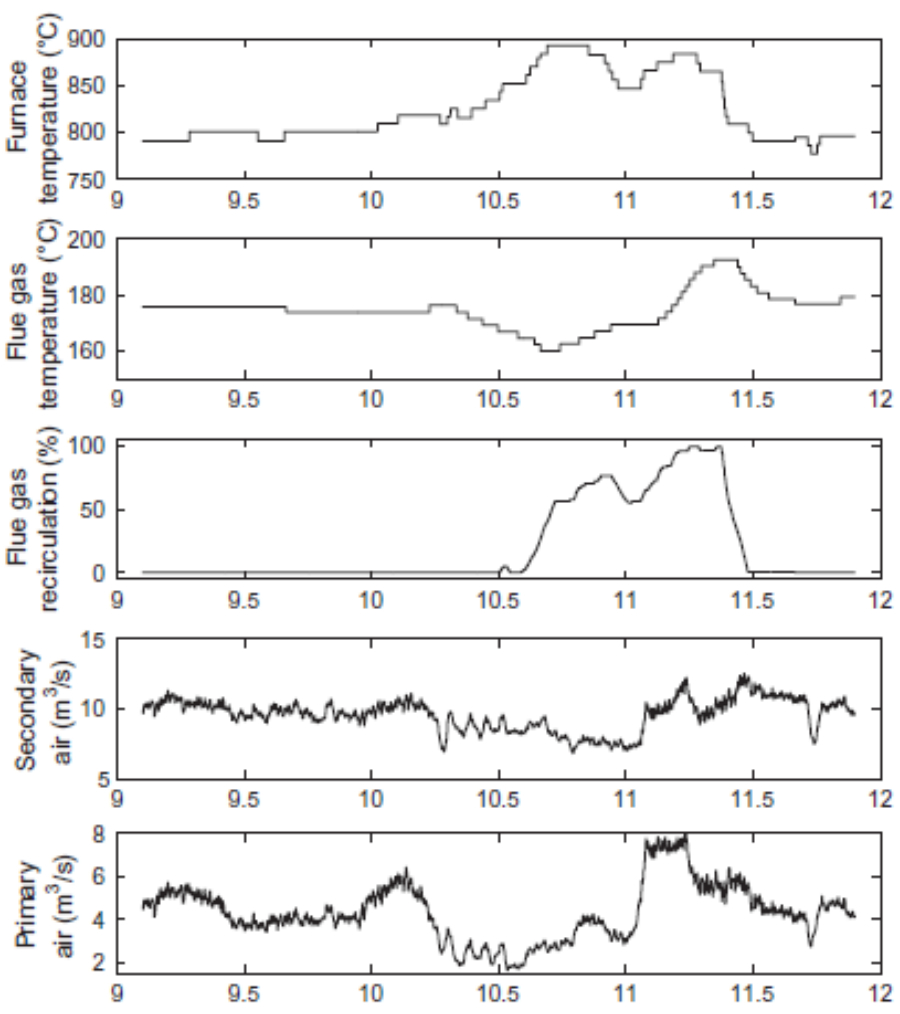

Fig. 13. Boiler measurements during the third test, including furnace temperature, flue gas temperature, and changes in the flue gas fan speed, secondary air flow, and primary air flow as reactions to changes in the moisture content of fuel flow. 


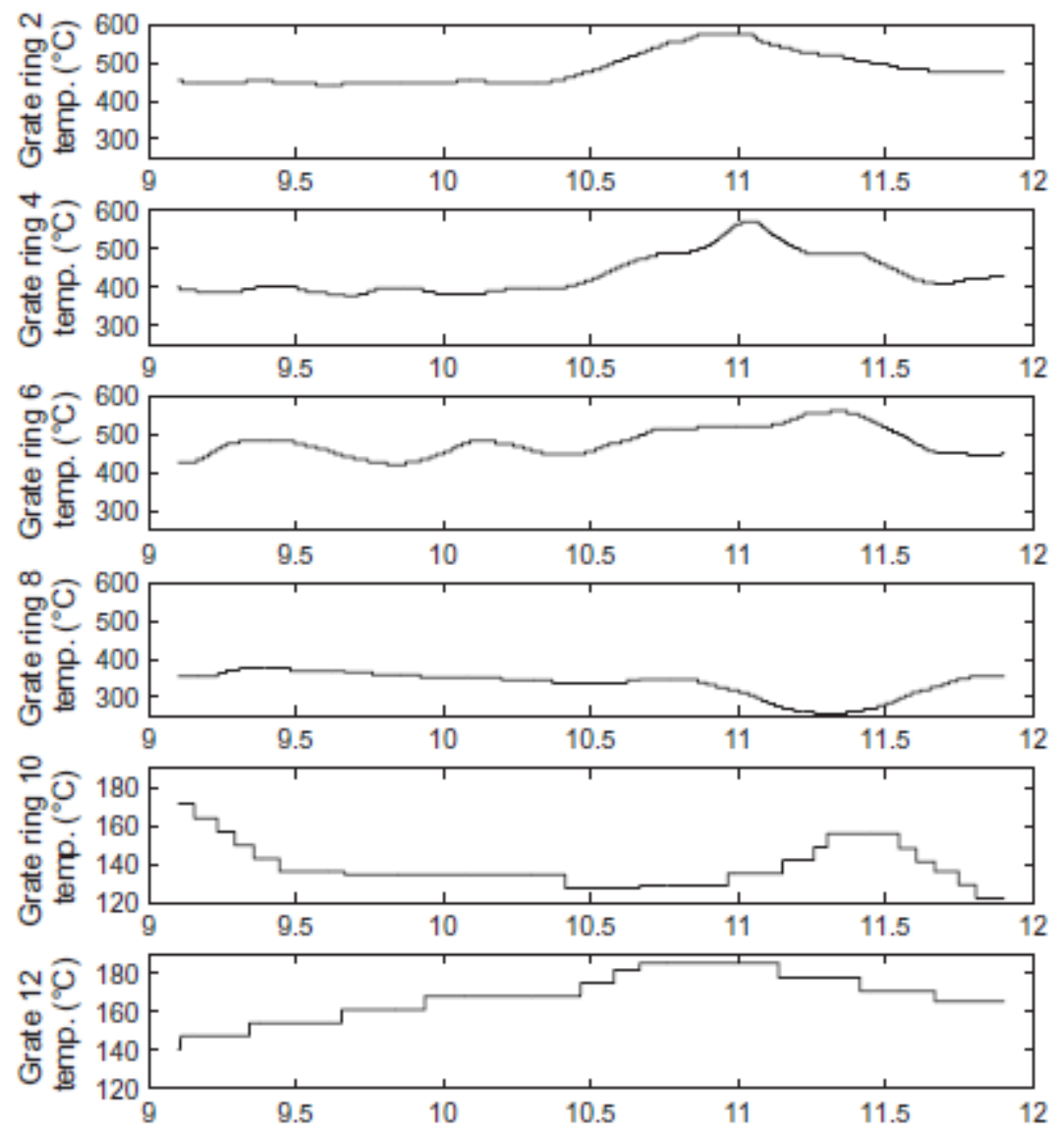

Fig. 14. Grate temperatures during the third test. The grate rings are numbered from the center (grate ring 2 ) to the edge of the grate (grate ring 12).

The estimated combustion power (CP) values are shown in Figs. 6, 9 and 12 to show how moisture in the fuel flow affected the drum pressure. In addition, Table 5 shows the time delays calculated using the Pearson cross-correlation function and the time constants of the first order transfer functions based on the estimated combustion power values and various measurements. The time delay between the primary air measurement values and the calculated $\mathrm{CP}$ values was $30 \mathrm{~s}$ due to transport delay and combustion. The time delay and time constant between the measurement values of the fuel flow moisture and the measurement values of the evaporating moisture were $1309 \mathrm{~s}$ and $380 \mathrm{~s}$ respectively. The time constant between the calculated CP measurements and the drum pressure measurements was $1819 \mathrm{~s}$ due to the large volume of the drum. On the other hand, the time constant between the calculated CP measurements and the superheated steam temperature measurements was only $90 \mathrm{~s}$ the small size of the secondary superheater. The time delay in the $\mathrm{CP}$ estimation was $4 \mathrm{~s}$, which was caused by the time delay in measuring the flue gas oxygen content.

Table 5

The time delays calculated using the Pearson cross-correlation function and the time constants of the first order transfer functions based on the estimated combustion power values and various measurements

\begin{tabular}{lll}
\hline & Time delay $(\mathrm{s})$ & Time constant $(\mathrm{s})$ \\
\hline Primary air, CP & 30 & - \\
Moisture content in fuel flow, CP & 1309 & 380 \\
$\mathrm{CP}$, drum pressure & 0 & 1819 \\
$\mathrm{CP}$, superheated steam temperature & 0 & 90 \\
$\mathrm{CP}$, combustion power estimation & 4 & - \\
$\mathrm{CP}$, fuel moisture soft-sensor & $<60$ & - \\
\hline
\end{tabular}

In order to produce $24 \mathrm{MW}$ of combustion power with a fuel that has a moisture content of $26 \%$, a fuel flow of $1.8 \mathrm{~kg} / \mathrm{s}$ is required, and $1.8 \mathrm{MW}$ of the energy produced is used to evaporate the moisture. This means that the process actually produces $25.8 \mathrm{MW}$ of power to achieve an output of $24 \mathrm{MW}$. In order to produce $24 \mathrm{MW}$ of combustion power with a fuel whose moisture content is $54 \%$, a fuel flow of $3.2 \mathrm{~kg} / \mathrm{s}$ is required, and 4.2MW goes towards evaporating the fuels moisture. The moisture content of fuel in a BioGrate boiler 
is typical as high as $60 \%$, in which case the energy needed for moisture evaporation is $5.7 \mathrm{MW}$ and the necessary fuel flow is $3.9 \mathrm{~kg} / \mathrm{s}$. The fuel moisture soft-sensor can show such a high change in fuel moisture about 20-30 min before any steam or drum pressure oscillations, therefore providing new possibilities of utilizing some compensation method or advanced control such as model predictive control and make use of the soft-sensor to estimate, for instance, the state of the moisture in the furnace. Bauer et al. [4] derived a simple model for the grate combustion of biomass based on two mass balances for water and dry fuel. In addition, the test results of Bauer et al. [4] showed that the rate of water evaporation is mainly independent of the primary air flow. Based on these results, Kortela and Jämsä-Jounela presented an MPC control strategy in [24] that utilizes fuel flow and fuel moisture soft-sensors, and furnace state estimators to handle the inherent large time constants and long time delays of the BioGrate boiler.

The accuracy of the fuel moisture soft-sensor was investigated in the BioPower 5 CHP plant during the three tests by sampling fuel feed and by using the FT-IR analyzer. According to the fuel sampling, the wet fuels average moisture content was $54.4 \%$. In comparison, the soft-sensor estimated that the fuels average moisture content was $54.6 \%$. The dry fuels average moisture content was $25.9 \%$. The soft-sensor estimated that the fuels average moisture content was $27 \%$. This shows that the fuel moisture soft-sensor's estimations and the values of the moisture samples matched were very similar. The standard error of performance (SEP) of the soft-sensor is $3.6 \%$ when compared with FT-IR that has the combined error of $3.3 \%$ [13].

The dynamic behavior of the fuel moisture soft-sensor was studied in the BioPower CHP plant by producing a step function of moisture in the flue gases by feeding portions of dry biomass in between portions of wet fuel. The results, presented in Figs. 6-14, show that the fuel moisture soft-sensor responded to the step changes within 1 min compared with FT-IR in which the 1 min filter was used. In addition, the fuel moisture soft-sensor showed no sign of hysteresis, responding equally to both positive and negative changes in moisture content. This verifies that this method of detecting varying moisture is accurate and responsive enough so that it can be used to control air and fuel feeds.

\section{Conclusions}

A fuel moisture soft-sensor based on combustion power estimation and a dynamic model of the secondary superheater was presented in this paper. Three experiments were conducted to validate the fuel moisture soft sensor. Two fuels were used to test the moisture soft-sensor: spruce bark with an average moisture content of $54 \%$ and dry woodchips (spruce) with a moisture content of $20 \%$.

The results show that this fuel moisture soft-sensor predicts the moisture content in the furnace with good precision. Furthermore, the results of the tests show that the method is able to detect variations in the furnaces moisture content within seconds, therefore opening up new possibilities of utilizing some compensation method or advanced control such as model predictive control and make use of the soft-sensor to estimate, for instance, the state of the moisture in the furnace.

\section{References}

[1] Yin C, Rosendahl LA, Kær SK. Grate-firing of biomass for heat and power production. Prog Energy Combust Sci 2008; 34(6):725-54.

[2] Lian ZT, Chua KJ, Chou SK. A thermoeconomic analysis of biomass energy for trigeneration. Appl Energy 2010; 87(1):84-95.

[3] Siitonen S, Tuomaala M, Suominen M, Ahtila P. Implications of process energy efficiency improvements for primary energy consumption and CO2 emissions at the national level. Appl Energy 2010; 87(9):2928-37.

[4] Bauer R, Grölles M, Brunner T, Dourdoumas N, Obernberger I. Modelling of grate combustion in a medium scale biomass furnace for control purposes. Biomass Bioenergy 2010; 34(4):417-27.

[5] Nyström J, Dahlquist E. Methods for determination of moisture content in woodchips for power plantsa review. Fuel 2004; 83(7-8):773-9.

[6] Nordell A, Vikterlöf KJ. Measurements of moisture content in wood fuels with dual energy X-ray. Stockholm: Värmeforsk; 2000 Apr. ISSN: 0282-3772. Swedish.

[7] Ayalew G, Ward SM. Development of a prototype infrared reflectance moisture meter for milled peat. Comput Electron Agric 2000; 28(1):1-14. 
[8] Axrup L, Markides K, Nilsson T. Using miniature diode array NIR spectrometers for analysing wood chips and bark samples in motion. J Chemom 2000; 14(5-6):561-72.

[9] James WL, Yen Y-H, King RJ.A microwave method for measuring moisture content, density, and grain angle of wood. United States Department of Agriculture, Forest Service, Forest Products Laboratory; 1985 Mar. Research Note: FPL-0250. p. 9.

[10] Okamura S, Zhang Y. New method for moisture content measurement using phase shifts at two microwave frequencies. J Microw Power Electromagn Energy 2000; 35(3):175-8.

[11] Rosenberg E, Schatvet J, Høydal K. In-kiln measurements of moisture content in timber at Moelven Våler AS. In: Third European COST E15 workshop on wood drying: softwood drying to specific end-uses. 2001 Jun 11-13; Helsinki, Finland. VTT Building and Transport; 2001.

[12] Kortela U, Marttinen A. Modelling, identification and control of a grate boiler. In: Proceedings of 1985 American control conference; 1985 Jun 19-21; Boston, MA, USA. p. 544-9.

[13] Bak J, Clausen S. FTIR emission spectroscopy methods and procedures for real time quantitative gas analysis in industrial environments. Meas Sci Technol 2002;13(2):150-6.

[14] Jaakkola PT, Vahlman TA, Roos AA, Saarinen PE, Kauppinen JK. On-line analysis of stack gas composition by a low resolution FT-IR gas analyzer. Water Air Soil Pollut 1998; 101(1-4):79-92.

[15] Hermansson S, Lind F, Thunman H. On-line monitoring off fuel moisture content in biomass-fired furnaces by measuring relative humidity of the flue gases. Chem Eng Res Des 2011;89(11):2470-6.

[16] Kortela J, Jämsä-Jounela S-L. Fuel quality soft-sensor for control strategy improvement of the BioPower 5 CHP plant. In: Conference on control and fault-tolerant systems (SysTol'10); 2010 Oct 6-8; Nice, France. p. 221-6.

[17] Kortela J, Jämsä-Jounela S-L. Fuel-quality soft sensor using the dynamic superheater model for control strategy improvement of the BioPower 5 CHP plant. Int J Electr Power Energy Syst 2012; 42(1):38-48.

[18] Wärtsilä Biopower. Wärtsilä power plants: bioenergy solutions. Vaasa: Waasa Graphics; 2005.

[19] Effenberger H. Dampferzeuger. 1st ed. Germany: Springer; 2000.

[20] Kortela U, Lautala P. A new control concept for a coal power plant. In: Proceedings of the 8th IFAC world congress; 1981 Aug 24-28; Kyoto, Japan.

[21] Åström KJ, Bell RD. Drum-boiler dynamics. Automatica 2000; 36(3):363-78.

[22] Lu S. Dynamic modelling and simulation of power plant systems. Proc Ins Mech Eng Part A: J Power Energy 1999; 213(1):7-22.

[23] Lu S, Hogg BW. Dynamic nonlinear modelling of power plant by physical principles and neural networks. Int J Electr Power Energy Syst 2000; 22(1):67-78.

[24] Kortela J, Jämsä-Jounela S-L. Model predictive control dor BioPower combined heat and power (CHP) plant. In: 11th International symposium on process systems engineering; 2012. p. 435-39. 